\title{
KISSPEPTIN SYSTEM: A Multi-Homeostatic System
}

\author{
Olaniyan O.T ${ }^{1 *}$, Meraiyebu AB ${ }^{1}$, Auta K.B ${ }^{1}$, Dare J.B ${ }^{2}$, Anjorin Y.D ${ }^{3}$, Shafe \\ M. ${ }^{1}$. \\ ${ }^{I}$ Department of Physiology, Bingham University, Karu, Nasarawa, Nigeria \\ ${ }^{2}$ Department of Anatomy, Bingham University, Karu, Nasarawa, Nigeria \\ ${ }^{3}$ Department of Physiology, University of Abuja, Abuja, Nigeria
}

\begin{abstract}
The last decades have witnessed an upsurge of neuropeptides research. These substances regulate or influence various functions in the body like appetite, water intake, learning and memory, adaptive responses to environmental stress, thermoregulation and fever, social behaviour, and sleep. Kisspeptin (formerly known as metastin) is a protein that is encoded by the KISS1 gene in the Anteroventral periventricular nucleus (AVPV) and Arcuate nucleus (ARC) nuclei of the hypothalamus which was originally discovered in 1996 by Lee and Welch while conducting oncology research at the Pennsylvania State University College of Medicine. It couple to G-protein receptor ligand for (GPR54) G-protein receptor 54 (Messager et al, 2005). It is found to play many important physiological roles which include: initiation of puberty, anti-oxidative effect, regulation of prolactin release, glucose homeostasis, role in nutrition status and fertility, role in pregnancy, increases sensitivity of chemoreceptors on type 2 carotid bodies, anti-metastatic effect, hot flushes in post-menopausal women. Kisspeptins are so named because the arginine-phenylalanine residues are present at the amino terminal "ArgPhe-NH2"; all of the kisspeptin fragments have a C-terminal decapeptide that is critical for biological activity (Clements et al, 2001; Kotani et al, 2001).
\end{abstract}

\section{Introduction}

The last decades have witnessed an upsurge of neuropeptides research. These substances regulate or influence various functions in the body like appetite, water intake, learning and memory, adaptive responses to environmental stress, thermoregulation and fever, social behaviour, and sleep. One function may be regulated by several peptides, and a single peptide can be involved in different functions - a general approach is to find a coordinated physiological pattern, which appears "meaningful" in explaining how a given peptide may participate in complex physiological events.

Kisspeptin (formerly known as metastin) is a protein that is encoded by the KISSI gene in the Anteroventral periventricular nucleus (AVPV) and Arcuate nucleus (ARC) nuclei of the hypothalamus, coupled to G-protein receptor ligand for (GPR54) G-protein receptor 54 (Messager et al, 2005). Kisspeptins are also described as excitatory neuromodulatory peptides for multiple homeostatic systems including initiation of puberty, anti-oxidative effect, regulation of prolactin release, glucose homeostasis, role in nutrition status and fertility, role in pregnancy, increases sensitivity of chemoreceptors on type 2 carotid bodies, anti-metastatic effect, hot flushes in post-menopausal women. Kisspeptin is localized in the central nervous system like the hypothalamus (mainly the AVPV and ARC nuclei), pituitary (Kotani et al, 2001), cerebellum, cerebral cortex, thalamus and Pons-medulla (Muir et al, 2001) and moderately expressed in the Peripheral body organs; like the testes, pancreas, liver, small intestine, and also the placenta (Ohtaki et al, 2001). The Kiss 1 gene was originally identified as a human metastasis suppressor gene because of its ability to suppress melanoma and breast cancer metastasis (Lee et al, 1996). The primary translation product of the kisspeptin gene is a 145 -amino acid protein (Kisspeptin-145) (Xanvier and William, 2010). The kisspeptin-145 design predisposes its peptides for proteosome degradation and shows that cytosolic KP-145 would have a short half-life of about 4 days (Mitchell et al, 2006). Proteolytic cleavage of the precursor protein (kisspeptin-145) generates a 54-amino acid amidated peptide (Kp54), and over time, shorter kisspeptins have been isolated (Kp14 and Kp13), which are degradative products from Kp54, the shortest kisspeptins degradative product is the kisspeptin-10 (Kp10) (Xanvier and William, 2010). Kisspeptins are so named because the arginine-phenylalanine residues are present at the amino terminal "Arg-Phe-NH2"; all of the kisspeptin fragments have a C-terminal decapeptide that is critical for biological activity (Clements et al, 2001; Kotani et al, 2001).

\section{Historical Background}

Kisspeptins were originally discovered in 1996 by Lee and Welch while conducting oncology research at the Pennsylvania State University College of Medicine. The goal of the project was to examine metastasis 
suppression in melanoma and breast cancer cells. Lee and Welch observed that certain cell lines metastasized more readily than others, and that these cell lines had decreased expression of a metastasis suppressor gene, later designated as KiSS-1 (Lee et al, 1996). The gene was given its name because of its location on chromosome-1, the original nomenclature of the KiSS- 1 gene and its product (kisspeptin) was discovered at the Pennsylvania State College of Medicine in Hershey, therefore to associate this discovery with their hometown and its most famous product which was, "the Hershey chocolate Kiss" and incorporate the letters 'SS' (suppresser sequence); the scientists named the gene, "KiSS-1". By the "Rules for Nomenclature of Genes, Genetic Markers, Alleles, and Mutations in Mouse and Rat'; the authorities at the Mouse Genome Informatics renamed the gene, "Kiss1". However, the revised nomenclature has not yet been widely adopted and is therefore referred to as Kiss1 (the gene) and its messenger RNA as KiSS-1 mRNA, in keeping with current usage (Jeremy, 2006). In 1999, GPR54 is a $\mathrm{G}$ protein-coupled receptor, which was originally identified as an "orphan" receptor in the rat (Lee et al, 1999). Although GPR54 shares a modest sequence homology with the known galanin receptors, galanin apparently does not bind specifically to this receptor (Lee et al, 1999). In 2001, three teams of investigators which are Kotani et al, 2001; Muir et al, 2001; Ohtaki et al, 2001, discovered in quick succession that the natural ligand for GPR54 is a 54-amino-acid product of a gene called Kiss1 gene (Kotani et al, 2001; Muir et al, 2001; Ohtaki et al, 2001) and Subsequent mutant studies led to the discovery that inactivating mutation in KISS1 gene and in GPR54 gene causes failure to progress through puberty in man, resulting to a condition, hypogonadotropic hypogonadism (HH) (Lee et al, 1996; Kotani et al, 2001). Thus, it was concluded that Kisspeptin-GPR54 signaling is essential to initiate gonadotropin (LH/FSH) secretion at puberty (Gottsch et al, 2004). Still in 2001, three biologically active cleavage peptides of the kisspeptin gene (KiSS-1gene) product were isolated from the human placenta, the Kisspeptin fragments are KP-54, KP-13 and KP-10 (Kotani et al, 2001). In 2003, two groups discovered that in both the human and the mouse, mutations in GPR54 (encoding the kisspeptin receptor, also known as KISS1R) cause hypogonadotropic hypogonadism. This can be corrected by the administration of exogenous GnRH (Gonadotrophin releasing hormone). This observation was corroborated by studies of mice bearing targeted deletions of GPR54, where it was noted that reproductive dysfunction is apparently the only remarkable phenotypic anomaly associated with the mutation (Funes et al, 2003; Seminara et al, 2003); Thus showing that kisspeptin-GPR54 signalling is essential to initiate gonadotropin secretion at puberty and support reproductive function throughout human life. In 2008, an activating mutation in $K I S S 1 R$ was identified in a girl with central precocious puberty not only did this observation reinforce the notion that kisspeptin is an important gatekeeper of pubertal function in the human, but it was also the first identification of loss and gain-of-function mutations critical to the hypothalamic control of GnRH leading to opposite reproductive phenotypes (Teles et al, 2008).

\section{Gene Expression and Precursor Processing}

The KISS1 gene is located on the long arm of chromosome 1 (1q32). In humans and mice, the Kiss 1 gene consists of two coding exons downstream from at least one non-coding exon, the human promoter (p1) has been mapped immediately upstream of the non-coding exon and contains a TATA box and several potential SP1 (Specificity Protein 1) transcription factor binding sites (Xanvier and William, 2010). The SP1 transcription factor is a human transcription factor involved in gene expression. It belongs to the Sp (Specificity Protein) family of transcription factors. The protein is 785 amino acids long, with a molecular weight of $81 \mathrm{kDA}$ (Park et al, 2002). 


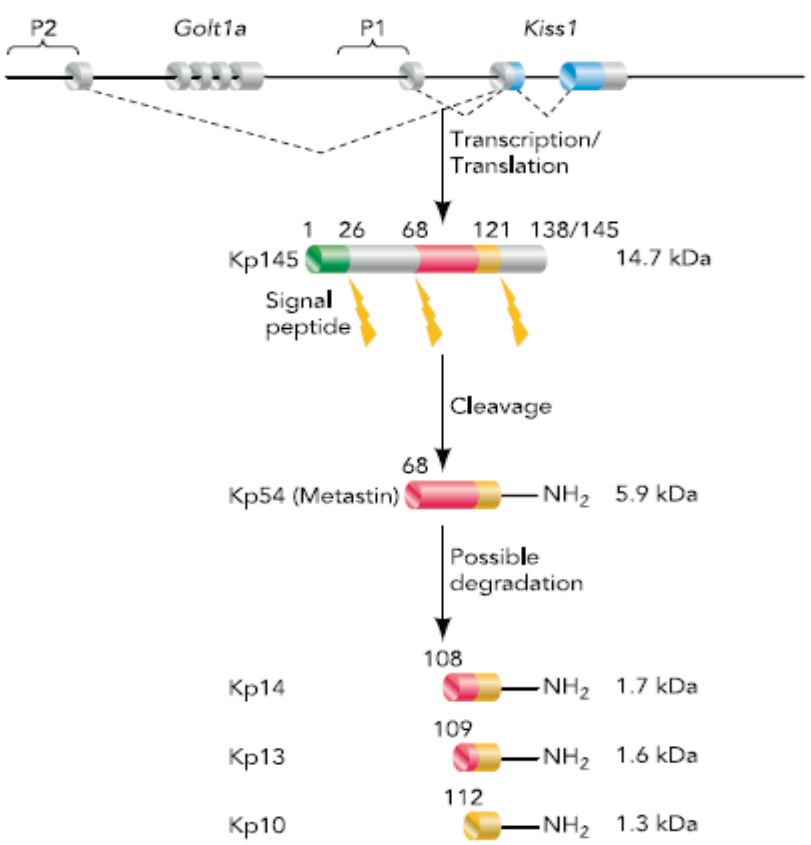

Fig. 1 shows the genetic expression of the KISS1 gene and breakdown of kisspeptin into smaller protein molecules from the precursor molecule which is kisspeptin 145 (Xanvier and William, 2010).

Kisspeptins are an overlapping set of amidated peptides encoded by the Kiss 1 gene. The KISS1 gene is located in close proximity to the Goltla gene (golgi transport 1 homolog A gene). The SP1 transcription factor has a zinc finger protein design, by which it binds directly to DNA and enhances gene transcription (Park et al, 2002). (These SP1 binding sites facilitate binding of AP-1/ SP1 and DRIP130/SP1 transcriptional activator complexes and contribute to basal promoter activity). Two SP1 binding site closest to the transcriptional site on the kisspeptin gene function together to facilitate transcriptional activation by estrogen (Xanvier and William, 2010). As in the figure above, the kisspeptin coding region (pale blue) is located within two exons of the Kiss 1 gene, in this diagram, one upstream non-coding exon (white) has been identified and the promoter (P1) in humans had been mapped immediately upstream of this exon (Xanvier and William, 2010).

The primary translation gene product is a 145-amino acid protein (Kisspeptin-145), which contains a secretory signal sequence (dark green as in the diagram above) (Xanvier and William, 2010). The full-length KP protein (KP-145) has a PEST sequence (proline, glutamic acid, serine, threonine and aspartic acid residue-rich sequence). Its design predisposes proteins for proteosome degradation and suggests that cytosolic KP-145 would have a short half-life of about 4 days (Kotani et al, 2001). Proteolytic cleavage of the precursor protein (kisspeptin-145) generates a 54-amino acid amidated peptide (Kp54), over time, shorter kisspeptins have been isolated (Kp14 and Kp13), which are degradative products from Kp54 (Xanvier and William, 2010).

KP-54, the long isoform of kisspeptin in human, cleaved from the amidated KP-145 precursor by the action of the enzyme furin/prohormone convertases (Kotani et al, 2001; Ohtaki et al, 2001; Harms et al, 2003). In rat and mouse, the long kisspeptin isoform is 52 amino acids long, with Arg-Try-NH2 at the C terminus instead of ArgPhe-NH2 as in humans (Tena-Sempere, 2006).

\section{Biochemistry of Kisspeptins}

The KiSS- 1 gene encodes a large polypeptide consisting of 145 amino acids, known as the pre-peptide to kisspeptins (precursor protein) i.e. kisspeptin 145 (Takino et al, 2003). The precursor protein is cleaved to form kisspeptin-54 (metastin) which is further cleaved to equally potent smaller fragments of 14, 13 and 10 amino acids in length. These fragments have subsequently been shown to bind and activate GPR-54 with equal potency (Kotani et al, 2001). 


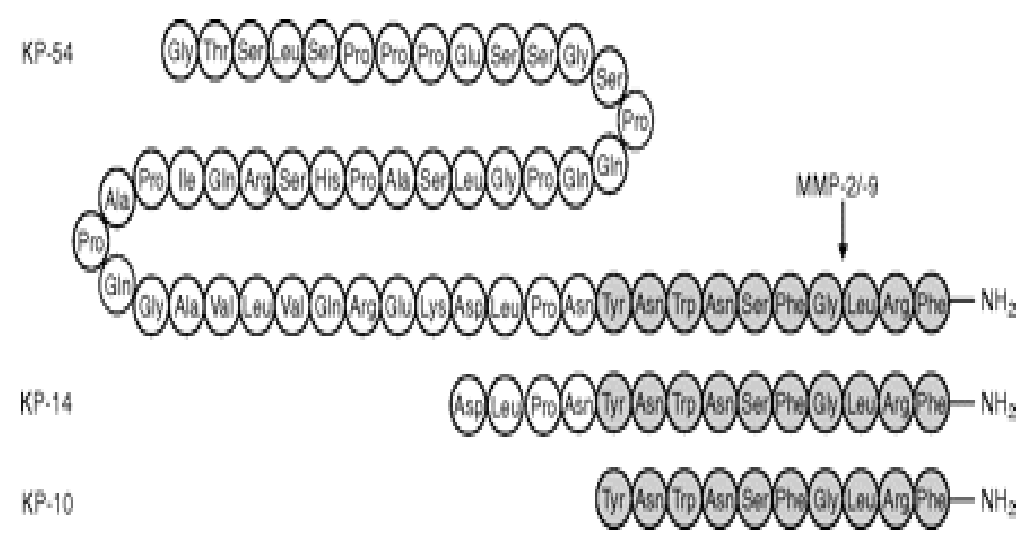

Fig. 2 (a) shows the human kisspeptin (KP-54) and the cleavage fragments KP-14 and KP-10 (Takino et al, 2003).

The final 10 amino acid fragment of the C-terminus has been used to determine the structure of Kisspeptins by nuclear magnetic resonance spectroscopy (NMR). Two studies have used NMR to determine the structure;

- The first used sodium dodecyl sulphate (SDS) micelles NMR method, which represents a negatively charged membrane. In this study kisspeptin-13 was utilised and residues Asn7 to Phe13 were found to form a stable helix structure (Takino et al, 2003).

- The second study utilised dodecylphosphocholine (DPC) micelles NMR mechanism which represent a membrane with a neutral charge, similar to the mammalian lipid membrane. Using kisspeptin-10, they showed that Trp3 to Phe10 contained several tight turn structures but no helices. The tight turns contained one $\beta$-turn from Tyr3 to Phe6; two miscellaneous type IV $\beta$-turns at Asn4 to Gly7 and Gly7 to Phe10; and finally one $\gamma$ turn from Ser5 to Gly7 (Lee et al, 1999). This suggests that hydrophobic environments may cause Kisspeptins to form a more ordered structure allowing them to bind and activate GPR-54.

The use of NMR to determine the structure of kisspeptin fragments has also shown that hydrogen bonds are important within these peptides, with eight hydrogen bonds being formed within Kisspeptin-13, allowing 16 hydrogen constraints. These are formed between residues Phe9, Leu11, Arg12 and Phe13. These four residues have also been shown to form a pharmacophore which is important for receptor binding. The pharmacophore consists of the phenyl ring of Phe9 with the Phe13 phenyl ring on top. These are then flanked by the positively charged Arg12, which is all in close proximity to the amide moiety. Even though the pharmacophore residues can form hydrogen bonds, it appears that the positive charge is more important for receptor binding (Takino et al, 2003).

All kisspeptins fragments have also been shown to contain a matrix metalloproteinase (MMP) mediated cleavage site, which is thought to be a mechanism to inactivate the protein. This site is at the C-terminus consisting of Phe-Gly-Leu-Arg, were MMP-2 and MMP-9 can cleave kisspeptin-54 between Gly51 and Leu52 (Takino et al, 2003).

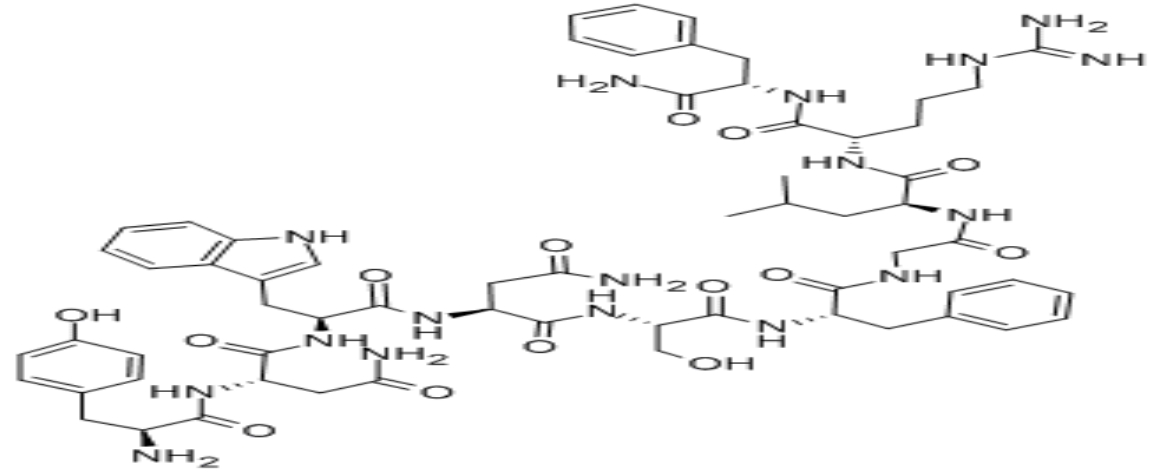

Fig. 2 (b) shows the biochemical structure of kisspeptin-10.

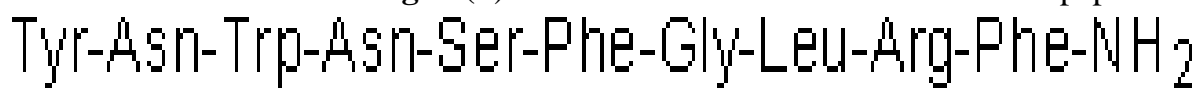

Fig. 2 (c) shows the amino acid present in kisspeptin-10 and the Arg-Phe amide family in kisspeptin. Chemical Name: KISSPEPTIN-10 Symbols: KISS1; HH13; KiSS-1 
Synonyms of kisspeptin: KISSPEPTIN-10; METASTIN (45-54).

\section{Mechanism of Action}

\section{Receptors and second messenger}

The kisspeptin receptor was initially classified as an orphan receptor, also known as GPR54 (G-protein coupled receptor 54); GPR54 is a member of the GPCR family member, was found to be the cognate receptor for kisspeptin five years after the hormone (kisspeptin) was first described (Kotani et al, 2001; Muir et al, 2001; Ohtaki et al, 2001) and is widely expressed in the central nervous system especially in the nuclei of the hypothalamus mainly AVPV (Anteroventral periventricular nucleus) and ARC (Arcuate nucleus) (Lee et al, 1999). G protein-coupled receptors (GPCRs) are the largest family of cell surface membrane receptors and regulate a variety of physiological responses by mediating transmission of extracellular signals into cells (Lee $e t$ $a l$, 1999). The kisspeptin receptor (GPR54/KISS1R) is a member of the rhodopsin family of seven transmembrane GPRs with structural similarities to the galanin receptor (Lee et al, 1999). Lee et al, (1999) cloned a novel G-protein-coupled receptor from rat brain and identified it (G-protein-coupled receptor) as a 396amino acid polypeptide. The kisspeptin receptor is a class A G-protein-coupled receptor coupled to $G_{q / 11}$, causing activation of the phospholipase $\mathrm{C}$ signaling pathway and resultant $\mathrm{Ca}^{2+}$ mobilization. Rat and human kisspeptin receptors share $85 \%$ sequence identity (Thompson et al, 2006). The closest structural relative of the kisspeptin receptor is the galanin receptor $\mathrm{GAL}_{1}$ with $45 \%$ homology; however galanin does not bind to it. KP10 , consisting of the $10 \mathrm{C}$-terminal amino acids of the full sequence, is the minimum fragment length needed to bind and activate the kisspeptin receptor (Lee et al, 1999).

Activation of the kisspeptin receptor by kisspeptins causes phosphorylation of focal adhesion kinase and paxillin, leading to formation of focal adhesion and stress fibers (Kotani et al, 2001; Ohtaki et al, 2001), and this correlates with the role of kisspeptin in inhibiting chemotaxis. Kisspeptin receptor stimulation has been demonstrated to inhibit calcineurin activity, which could also contribute to metastasis suppression (Navenot et al, 2005). GPR54/KISS1R (kisspeptin recetor) causes the depolarization of neuron through activating a cascade system by employing the phospholipase $\mathrm{C}$-second messenger system.

\section{Pathway}

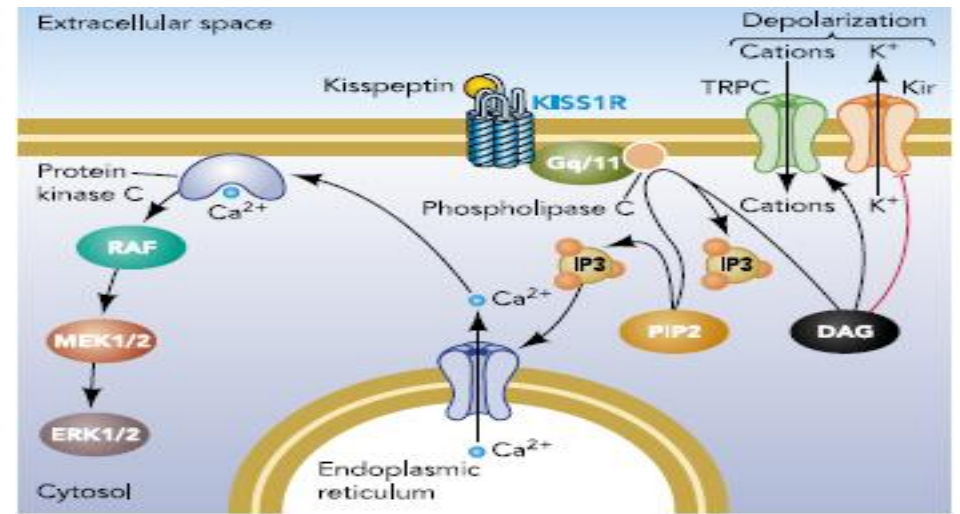

Fig. 3 shows the mechanism of kisspeptin receptor action and GnRH neuron depolarization (Xanvier and William, 2010).

Kisspeptin binding to its receptor (GPR54/KISS1R) activates the G-protein $\left(\mathrm{G}_{\mathrm{q} / 11}\right)$ and phospholipase $\mathrm{C}$ to cleave phosphatidylinositol biphosphate $\left(\mathrm{PIP}_{2}\right)$ into inositol triphosphate (IP3) and diacylglycerol (DAG) (Xanvier and William, 2010).

IP3 causes intracellular $\mathrm{Ca}^{2+}$ release from the mitochondria and endoplasmic reticulum, this $\mathrm{Ca}^{2+}$ ions act through the calcium-calmodulin second messenger system to cause activation of calmodulin-dependent protein kinases through phosphorylation. One specific function of calmodulin is to activate myosin light-chain kinase, which acts directly on the myosin of smooth muscle to cause smooth muscle contraction (Guyton and Hall, $12^{\text {th }}$ edition).

Diacylglycerol (DAG) activates protein kinase $\mathrm{C}$ and a kinase phosphorylation cascade resulting in the release of arachidonic acid and stimulation of the mitogen-activated protein kinase (MAPK), extracellular signal-regulated kinase (ERK) 1 and ERK2 kinase (Kotani et al, 2001). This has been attributed to increased phosphorylation of mitogen-activated protein kinase (MAPK). Additionally, other kinases are reported to be 
activated by KISS1 including myeloid cell leukemia 1, calcium/calmodulin-dependent kinases and tyrosine kinases (Becker et al, 2005) in the cytosol, which causes the breakdown of a large number of proteins in an array such that a very little amount of the hormone (kisspeptin) will cause a strong effect on the target organ (Xanvier and William, 2010) as seen in the Fig 3 above. DAG also stimulates GnRH neuron depolarization by activation of a nonselective cation channel (TRPC) and inhibition of an inwardly rectifying potassium channel (Kir) (Xanvier and William, 2010). Therefore kisspeptins act directly on GnRH neurons to induce a sustained depolarization event and increase the rate of action potential firing (Xanvier and William, 2010).

\section{Metabolism}

Kisseptin is metabolized by the prolyl endopeptidase (PREP) also known as post-proline cleaving enzyme, which is a large cytosolic enzyme that belongs to a distinct class of serine peptidases. Endopeptidase24.15 cleaves several substrates found in the hypothalamic/pituitary/gonadal axis, including gonadotropinreleasing hormone $(\mathrm{GnRH})$ and the opioid peptides of the dynorphin family; thereby causing the Dynorphin unit of the KNDy to cause decrease in kisspeptin expression in the hypothalamus (Yamada et al., 2007). A developmental regulation of EP-24.15-specific activity is apparent in anterior pituitary, hypothalamus, and in the gonads. EP-24.15 is increased in the preoptic area and is decreased in the anterior pituitary in both male and female rats prior to puberty (Pierotti et al, 1985).

\section{Puberty Initiation}

\section{Physiology of Kisspeptin}

Puberty is the onset of adult sexual life occurring in both males and females, it is the process of physical changes in which the body matures into an adult body capable of sexual reproduction, and it is also a period of mental transition. The period of puberty is caused by a gradual increase in gonadotrophic hormones such as follicular stimulating hormone (FSH) and lutenizing hormone (LH) secreted by the pituitary to the gonads (the ovaries in female and the testis in males), beginning averagely at about 8 years, and usually culminating in the onset of puberty and menstruation between ages 11 and 16 years in females, averagely at 13 years and between 13 to 17 years in males, averagely at 14 years (Guyton and Hall, $12^{\text {th }}$ edition).

The hypothalamus does not secrete significant quantities of GnRH during childhood as studies have shown that the hypothalamus itself is capable of secreting these reproductive hormone such as follicular stimulating hormone(FSH), but the appropriate signal from some other area of brain in the hypothalamus to cause the secretion is lacking (Messenger et al 2005). Stimulatory signals originating from the circadian clock in the suprachiasmatic nucleus ( $\mathrm{SCN}$ ) mediate the LH surge by activating kisspeptin neuron mainly in the Anteroventral periventricular nucleus (AVPV) (Wilbur et al, 2011).

Kisspeptin has since been identified as a major regulator of the hypothalamic-pituitary-gonadal axis (HPG), governing pubertal onset in an increasing number of species, by stimulating gonadotropin release (Dhillo et al, 2005; 2007). The activity of the HGP axis (the hypothalamic-pituitary-gonadal axis) is heighten by the release of kisspeptin into the body. Therefore during the initiation of puberty, the kisspeptin produced in the AVPV (Anteroventral periventricular nucleus) and ARC (arcuate nucleus) in the hypothalamus trigger the GnRH neurons to secrete GnRH (Gonadotrophin releasing hormone). The gonadotrophin releasing hormone travels down the anterior portion of the pituitary via the hypophyseal portal system and binds to receptors on the secretory cells of the adenohypophysis (Charlton, 2008). In response to GnRH stimulation these cells (cells of the adenohypophysis) produce LH (lutenizing hormone) and FSH (follicular stimulating hormone) which travel in the blood stream (Vadakkadath, 2005). These two hormones play an important role in communicating with the gonads, which therefore leads to an increase in the gonadal hormones such as testosterone and estrogen which will lead to the development of the physiological and behavioural changes in puberty (Meethal et al, 2009). Sex steroids (such as estrogen, testosterone and progesterone), Gonadotrophins (follicular stimulating hormone and lutenizing hormone) have been shown to affect behaviour, as these sex steroids and hormones affect the brain structure and functioning (Hines, 1982). Estrogenic hormones binding to particular neurons in a limbic-hypothalamic system stimulate and cause changes on the molecular biology of medial hypothalamic neurons which are central in establishing the first circuit for a mammalian behaviour, for instance, in the femaletypical mating behaviour, "lordosis", estradiol has the ability to facilitate transcription from six genes whose products are important for lordosis behaviour. This proves that sex steriods can turn on genes which are associated with sensible behavioural consequences (Pfaff et al, 2000). Testosterone levels which rise as a result of increased GnRH due to release of kisspeptin from the hypothalamic neurons, have been shown to relate to aggression and sex drive, testosterone creates synaptogenesis by promoting neurite development and migration, therefore men tend to be more competitive or aggressive than women (Shephard, 2009). 
In females FSH (follicle-stimulating hormone) and LH (lutenizing hormone) act primarily to activate the ovaries to produce estrogen and to regulate the menstrual cycle and ovarian cycle (Meethal et al, 2009).

In males lutenizing hormone (LH) stimulates the interstitial cells located in the testes to produce testosterone, and follicle-stimulating hormone (FSH) plays a role in spermatogenesis (Meethal et al, 2009). At birth follicle-stimulating hormone (FSH) and lutenizing hormone (LH) levels are elevated, and the females have a lifetime supply of primary oocytes; these hormonal levels (FSH and LH) decrease and remain low through childhood. During puberty the HPG axis is activated by the secretions of estrogen from the ovaries or testosterone from the testes (Downs, 2009). Once activated, the HPG axis continues to function in men for the rest of their life but becomes deregulated in women, leading to menopause. This deregulation is caused mainly by the lack of oocytes that normally produce estrogen to create the positive feedback loop; over several years, the activity the HPG axis decreases and women are no longer fertile (Downs, 2009).

Sex steroids (estrogen, progesterone, androgen and testosterone) provide feedback loops that allow the gonads to communicate with the hypothalamus to regulate GnRH release. This regulatory/feedback effect of the sex steroid was found to be in association with kisspeptin (Xanvier and William, 2010), therefore an investigation of the epigenetic mechanism by which sex steroids (mainly estrogen) regulates the expression of the kisspeptin-encoding gene (Kiss1) to mediate the positive feedback effect of kisspeptin on GnRH release was carried out;

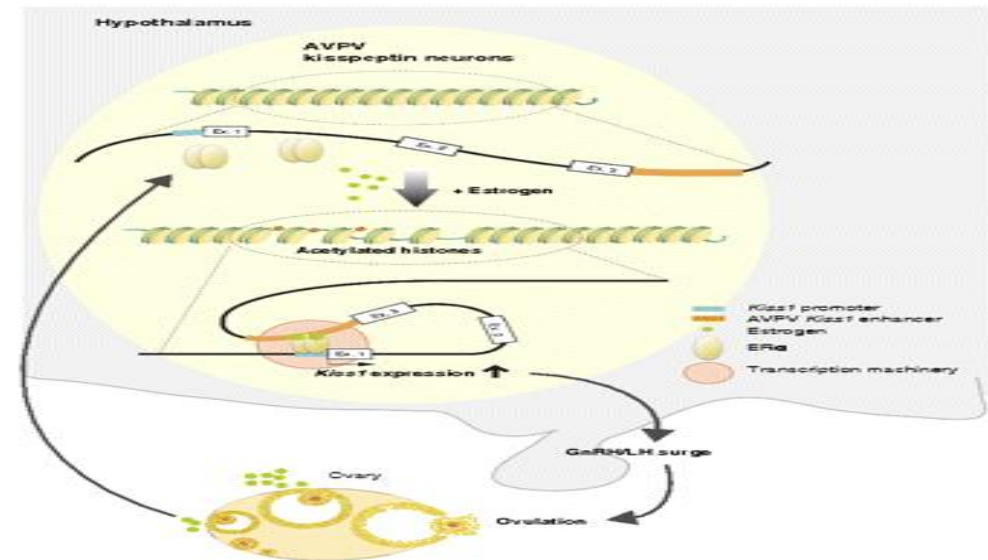

Fig. 4 (a) shows the result of the investigation of the epigenetic mechanism by which estrogen regulates the expression of the kisspeptin-encoding gene Kiss1 to mediate its positive feedback effect on GnRH release (Junko et al, 2012).

As in the figure above, the Kiss1 gene looping induced by estrogen stimulation in the AVPV, it shows two possible states of the mouse Kiss1 gene locus during transcriptional regulation in the AVPV. (Upper) In the absence of estrogen, a factor-mediated association between the Kiss 1 promoter and the $5^{\prime}$ upstream region forms a chromatin loop (a chromatin loop occurs when stretches of genomic sequence that lie on the same chromosome are in closer physical proximity to each other than to intervening sequences) which will prevent transcription. (Lower) In the presence of estrogen, the estrogen-ER $\alpha$ complex induces histone acetylation in the Kiss1 promoter region, causing a relaxed chromatin structure and consequently enhances the formation of a chromatin loop between the Kiss 1 promoter and the 3' enhancer region, promoting transcription; this indicates that only in the presence of estrogen does kiss1 promoter enhance the transcription of the KISS1 gene which induces GnRH surges by acting on the kisspeptin neurons in the AVPV to release kisspeptin molecules that activate GnRH neurons in the preoptic area of the hypothalamus (Junko et al, 2012).

The number of $(\mathrm{GnRH})$ neurons that can respond to kisspeptins increases during puberty even though the expression levels only change slightly, suggesting posttranslational maturation of GPR54/KISS1R function with puberty control by the master clock of the body, the suprachiasmatic nucleus (SCN) of the hypothalamus (Moore et al, 1987). The ER $\alpha$-expressing neurons ( $\alpha$-isoform of the estrogen receptor) which are expressed within the AVPV are direct targets of the SCN (Palm et al, 1999). 


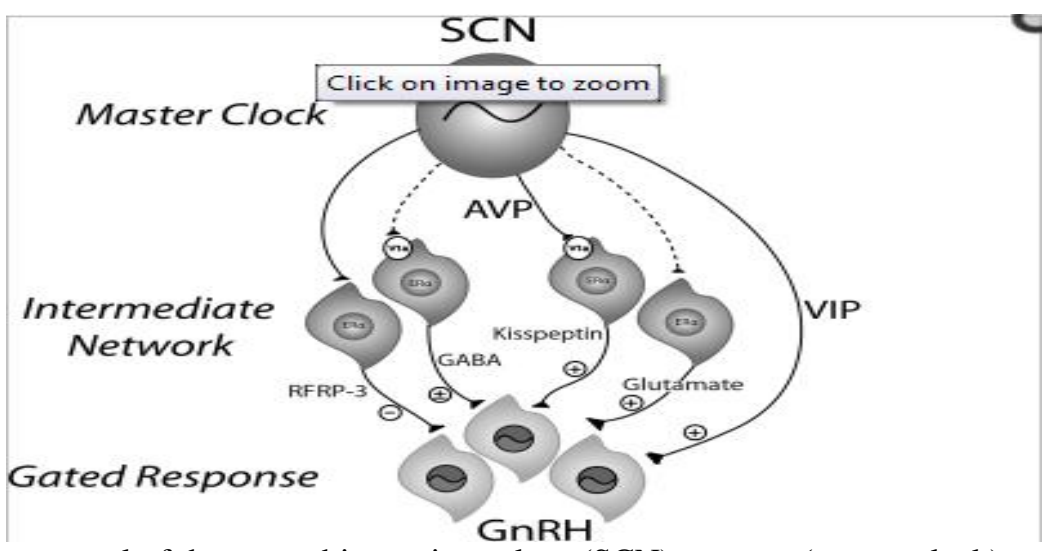

Fig. 4 (b) shows the control of the suprachiasmatic nucleus (SCN) neurons (master clock) on kisspeptin release to stimulate GnRH neurons (de la Iglesia et al, 2006).

From the above figure, the suprachiasmatic nucleus ( $\mathrm{SCN}$ ) neurons express plasma arginine vasopressin (AVP) in vivo which activates expression of the V1a receptor (vasopressin receptor) neurons in the dorsomedial hypothalamus (de la Iglesia et al, 2006). The activated V1a receptor (vasopressin receptor) activate the ER $\alpha$ expressing neurons ( $\alpha$-isoform of the estrogen receptor) located within the AVPV, the ER $\alpha$-expressing neurons express kisspeptin neurons to release kisspeptin; the ER $\alpha$-expressing neurons ( $\alpha$-isoform of the estrogen receptor) also express other neurons which release a number of other hormonal substances such as $\gamma$ aminobutyric acid (GABA), Gonadotropin inhibitory hormone (RFRP-3), glutamate and Vasoactive intestinal polypeptide (VIP) which send inhibitory and stimulatory afferents to the GnRH neurons. The GnRH neurons, in turn, receive input from these inhibitory and stimulatory afferents as well as direct VIPergic input from the $\mathrm{SCN}$. In turn, the consequent response of the GnRH system will depend on the sum total of positive and negative influence (de la Iglesia et al, 2006).

Regulatory effects come from kisspeptin neurons in the ARC nucleus in the hypothalamus through the (kisspeptin, neurokinn B and dynorphin) KNDy connection formed in the ARC nucleus.

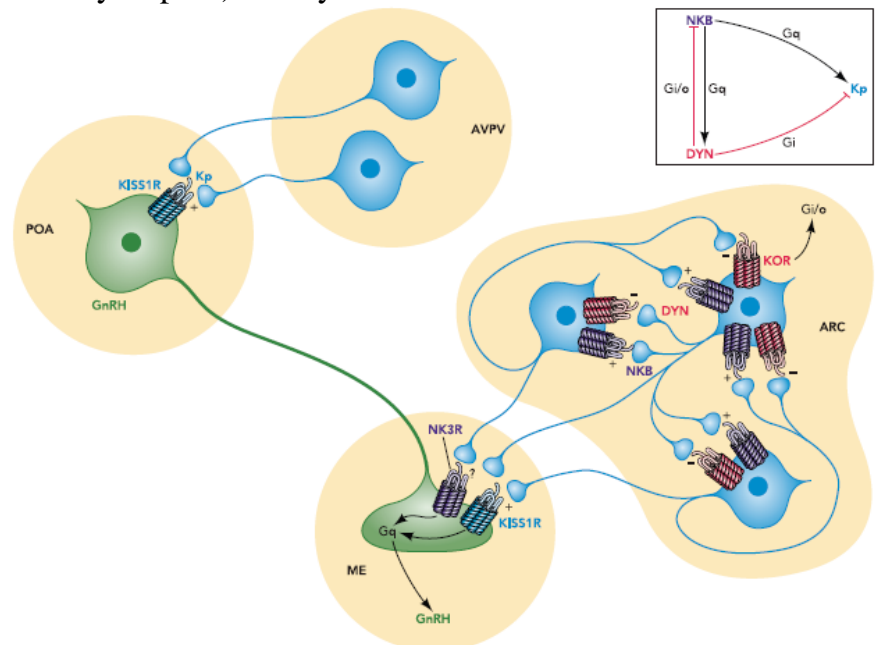

Fig. 4 (c) shows the connection between kisspeptin, dynorphin A and neurokinin B (KNDy) neurons and feedback mechanism to regulate GnRH release (Xanvier and William, 2010). Where; ME (median eminence), NKB (neurokinin B) KISS1R (kisspeptin recetor), GnRH (gonadotrophin releasing hormone), DYN (dynorphin A), ARC (arcuate nucleus), AVPV (Anteroventral periventricular nucleus), KOR (dynorphin A recetor), NK3R (neurokinin B receptor), POA (preoptic area).

The kisspeptin neurons in the ARC serve in the negative feedback control of GnRH secretion (de Roux et al, 2003). Kisspeptin neurons in the ARC have been found to co-express Dynorphin A (DYN) and Neurokinin B (NKB), abbreviated as the KNDy (kisspeptin, neurokinn B and dynorphin) subpopulation. 96\% of ARC kisspeptin neurons express the neurokinin B receptor gene ( $\mathrm{Nk} 3 \mathrm{r}$ ), but only $20 \%$ of ARC kisspeptin neurons express the dynorphin receptor gene (Kor) (Xanvier and William, 2010).

One primary neuro-anatomical observation leading to the identification of the KNDy subpopulation was that; each of the component neuropeptides (kisspeptin, Neurokinin B, and Dynorphin A), when examined in dual-label studies showed a very high degree of colocalization with gonadal hormone steroid receptors, 
specifically the $\alpha$-isoform of the estrogen receptor (ER $\alpha)$, the progesterone receptors (PR), and the androgen receptor (Xanvier and William, 2010). Because colocalization of the three KNDy peptides in the ARC appears to be unique among brain areas, colocalization of multiple KNDy peptides in the same axon terminal can be used to determine the efferent targets of this subpopulation; using this approach, it was demonstrated in the human that KNDy cells provide direct inputs to GnRH neurons in the pre-optic area (POA) and median eminence (ME) at the level of their cell bodies and dendrites showing that kisspeptin, NKB, and DYN fibers directly contact GnRH at the level of their cell bodies and their neuro-secretory terminals in the median eminence (Dahl et al, 2009). Based on observations, it has been proposed that synchronous activity of KNDy neurons is controlled by stimulatory actions of NKB and inhibitory actions of DYN on these KNDy neurons and their output to GnRH neurons is primarily via kisspeptin. Each GnRH pulse is triggered by an initial increase in NKB from a few KNDy neurons, which stimulates further NKB release; the resulting positive feedback loop produces release of kisspeptin onto GnRH neurons and hence an extremely rapid increase in GnRH secretion that occurs at the onset of a pulse. The positive feedback of NKB on the KNDy neurons also stimulate release of DYN, and the inhibitory actions of this DYN on KNDy neurons first begins to hold kisspeptin release in check and, after a few minutes, completely suppresses the activity of KNDy neurons, terminating the GnRH secretory episode and preventing any GnRH secretion between pulses. The action of DYN on KNDy neurons will also suppress DYN release, which eventually allows increased firing and the NKB release that triggers the next GnRH pulse (Moenter et al, 1992).

Although, there is also compelling evidence that changes in KNDy cells occur as a part of the process of normal aging in association with menopause as it has long been known that in the brains of postmenopausal women, there is selective hypertrophy of neurons of the arcuate nucleus of the human hypothalamus (Sheehan $e t$ $a l, 1996)$. The important role that KNDy neurons appear to play in the control of the GnRH system is interesting in light of the history of reproductive neuroendocrinology. The ARC was the hypothalamic nucleus that Ernst Knobil and others originally identified as the site of the GnRH pulse generator and has long been considered a key locus in steroidal control of GnRH secretion (Sheehan et al, 1996).

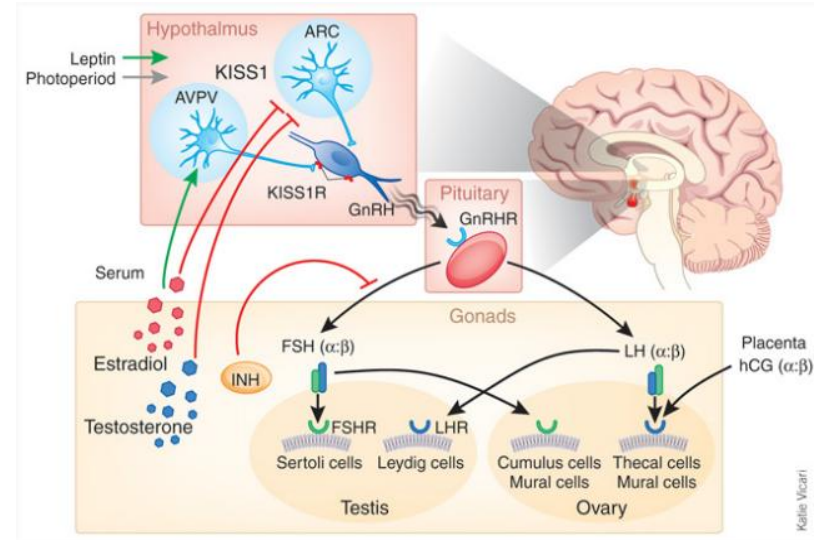

Fig. 4 (d) shows the process involved in puberty initiation.

As GnRH neurons are the final central pathway controlling the onset of puberty, Kisspeptin potently activates GnRH release via G protein-coupled receptor 54 (GPR54) (Xanvier and William, 2010). The GnRH acts on the anterior pituitary to stimulate the release of the gonadotrophic hormones, (luteinizing hormone (LH), and follicle stimulating hormone (FSH)). The gonadotrophic hormones act on the gonads (ovary and testes) to stimulate to produce sex steroids (testosterone in males and estrogen and progesterone in females), required for sexual maturation and gametogenesis (spermatogenesis in males and oogenesis in females) which is the maturation of accessory sex organs, and to provide hormonal feedback loops that regulate GnRH and gonadotrophic hormone (FSH and LH) release under different physiological conditions (Xanvier and William, 2010).

\section{Anti-metastatic Effect}

\section{Other Physiological roles}

The KiSS-1 gene that encodes kisspeptins was first discovered as an anti-metastasis gene made from observations of an anti-metastatic effect of chromosome 6 in human melanoma cell lines (Becker et al, 2005; Takino et al, 2003). However, mapping showed that this gene was in fact located on chromosome 1q32 (which is the chromosome upon which kiss1 gene is located), not chromosome 6 (Lee et al, 1996). Tumor necrosis factor-alpha (TNFa) induces cancer development and metastasis, which is prominently achieved by nuclear factor-kappa (NF-kB) activation. TNFa-induced NF-kB activation enhances cellular mechanisms including proliferation, migration, and invasion. However studies conducted showed that KiSS1 suppresses the migration 
of breast cancer cells by inhibiting TNFa-induced NF-kB (nuclear factor-kappa) pathway and RhoA activation as KP10 inhibited TNFa-induced cell migration and RhoA GTPase activation, thus KiSS1 inhibits TNFainduced NF-kB activation via down-regulation of RhoA-mediated TNFa-induced NF-kB (nuclear factor-kappa) activation and suppression of breast cancer cell migration and invasion (Lee, 1996) and inhibits MMP-9 (matrix metalloprotease) expression by reduced NF-kB binding to the MMP9 promoter, to cause an inhibition of cell (Mitchell et al, 2006).

\section{In Pregnancy: Implantation and Placentation}

The human placenta has a high expression of both the KiSS-1 and GPR54 genes. Plasma kisspeptin levels increase several thousand folds in pregnancy. In the human placenta, KiSS-1 is located within the syncytiotrophoblast cells (Bilban et al, 2004). The non-pregnant plasma kisspeptin is around $1.3 \mathrm{fmol} / \mathrm{ml}$, this increases to $\sim 1230 \mathrm{fmol} / \mathrm{ml}$ in the first trimester and rises to $\sim 9590 \mathrm{fmol} / \mathrm{ml}$ at term, then after delivery returns to normal levels within 5 days suggesting the source of kisspeptin is the placenta (Bilban et al, 2004) and also suggests a role in implantation and placentation, therefore KiSS-1 appears to be a conserved regulator of placentation. The role of the Kisspeptin-10 has been shown to inhibit trophoblast migration without affecting proliferation as kisspeptin is also located in the trophoblast giant cells within the rat placenta. Trophoblast invasion is important to allow remodelling of the maternal arteries, to provide sufficient blood flow to the developing foetus (Bilban et al, 2004).

\section{Increases Sensitivity of Chemoreceptors on the Carotid Body}

Immunohistochemistry revealed diffuse expression of kisspeptins and its receptor in type 1 cells of both human and rat carotid bodies. Immuno-stained cells were distributed both in the centre and in the periphery of the lobules of the Type 1 carotid bodies, conversely, no kisspeptins or its receptor immuno-stainings were observed in type II cells (Porzionato et al, 2008). Kisspeptin and kisspeptin receptor were found to be expressed in glomic type I cells through immunohistochemistry. A glomus cell is a peripheral chemoreceptor, located in the carotid bodies and aortic bodies, which help the body, regulate breathing. The glomus cells have a high metabolic rate and good blood perfusion and thus are sensitive to changes in arterial blood gas tension. In the carotid body, glomic type I cells release many neurotransmitters and peptide neuromodulators that play a role in the regulation of chemoreceptor (Iturriaga et al, 2004). Kisspeptins could also show trophic actions on glomic cells, in the pre- and postnatal periods the carotid body undergoes structural changes mediated by trophic factors, which include brain-derived neurotrophic factor, glial cell line-derived neurotrophic factor, ciliary neurotrophic factor, insulin-like growth factors-I and II, basic fibroblast growth factor, epidermal growth factor, transforming growth factor-alpha and -beta1, interleukin-1beta and -6, tumour necrosis factor-alpha, vascular endothelial growth factor, and endothelin-1 (ET-1) (Porzionato et al, 2008). These structural changes include the carotid body volume increase, proliferation of type I, type II, endothelial and Schwann cells lining peripheral nerve fibers and increased number of synapses between type I and II cells (Porzionato et al, 2008) which enhances activity of chemoreceptor. Expressions of both KISSI and KISS1R were also found in ganglion cells of the human and rat superior cervical ganglia showing a role of kisspeptins in the modulation of the sympathetic function, mainly through autocrine or paracrine mechanisms.

\section{Role in Nutritional Status and Fertility}

It has long been recognized that an intimate relationship exists between nutritional status and fertility. Leptin, a peptide hormone synthesized and secreted by adipocytes conveying information about body energy stores and nutritional status and regulates appetite for food in humans (Zhang et al, 1994). The level of circulating leptin is proportional to fat mass and falls in both animals and humans following weight loss. Mice with low circulating leptin have delayed puberty and are infertile as a consequence of hypogonadotrophic hypogonadism. Also, in an experiment, leptin was administered to juvenile wild-type mice; this led to the acceleration of puberty (Chehab et al, 1996). In the type II diabetes, which causes obesity and hypogonadism is common, disturbed kisspeptin function can be rescued by leptin (Castellano et al, 2006). The link between leptin and kisspeptin was further strengthened by observations that leptin can influence the expression of kisspeptin in the arcuate nucleus of mice, as the Kiss1 neurons express leptin receptors. 


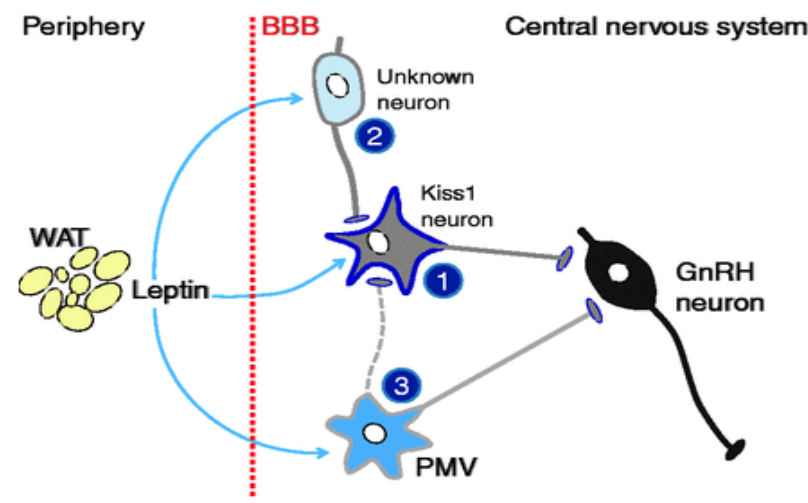

Fig. 5 shows the potential mechanisms for transmitting the actions of leptin, produced by the white adipose tissue (WAT) to GnRH neurons in the basal forebrain, to control of the gonadotropic axis (Zhang et al, 1994).

Animal models offer several explanations and show that reduced leptin signaling leads to reduced GnRH neuronal activity; this may be due to decreased hypothalamic Kiss1 expression, a potent regulator of GnRH/LH/FSH release. The Kiss1 system participates in transmitting metabolic information to the GnRH neurons, thus providing a bridge between metabolic regulation and fertility. Infertility in overweight/obese males may be explained by leptin insensitivity. This implies a possible role for the KISS1 system in human obesity-related male infertility (Zhang et al, 1994).

\section{Glucose Homeostasis}

RT-PCR and Immunohistochemistry were used to detect expression of KISS1 and GPR54 mRNAs and the production of KISS1 and GPR54 in human and mouse islets and in beta (MIN6) and alpha- (alphaTC1) cell lines (Hauge-Evans et al, 2006), but were not detected in the exocrine pancreas. Exposure of mouse and human islets to KISS1 caused a stimulation of glucose-induced $(20 \mathrm{mmol} / \mathrm{l})$ insulin secretion, in contrast, KISS1 inhibited insulin secretion from MIN6 cells at both 2 and $20 \mathrm{mmol} / \mathrm{l}$ glucose and had no significant effect on glucagon secretion from mouse islets, this shows that the GPR54/KISS1 system is expressed in the endocrine pancreas, where it influences beta cell secretory function.

\section{Anti-oxidant Effect}

The activities of catalase, superoxide dismutase (SOD), xanthine oxidase (XO), adenosine deaminase (AD) and level of malondialdehyde were studied in liver tissue. Serum samples were separated for total antioxidant capacity (TAC), total oxidant status (TOS), alanine aminotransferase (ALT), aspartate aminotransferase (AST), alkaline phosphatase, blood urea nitrogen (BUN), cholesterol, high-density lipoprotein (HDL) and triglyceride. Kisspeptin was seen to increase the activities of SOD and catalase (Aydin et al, 2010). SOD is an oxido-reductase which catalyzes the dismutation of the superoxide anion into molecular oxygen and hydrogen peroxide. CAT detoxifies hydrogen peroxide, CAT is a well-known antioxidative enzyme and has been implicated in protection against hydrogen peroxide, and their localization is limited to the peroxisome (Aydin et al, 2010).

\section{Regulates Prolactin Release}

Szawka et al. investigated kisspeptin's action in the control of secretion of hypothalamic dopamine (DA) and pituitary prolactin (PRL) in adult rats (Szawka et al, 2010). Using the double-label immunofluorescence combined with confocal microscopy, KISS-IR fibers were shown to be in close apposition to hypothalamic dopamine (DA) perikarya in the arcuate nucleus, indicating that the kisspeptin neurons likely communicate with the DA (hypothalamic dopamine) neurons that regulate PRL (prolactin). The mechanism of the Prolactin (PRL) regulation occurs directly at the level of the tuberoinfundibular dopaminergic (TIDA) neurons located in the arcuate nucleus. The hypothalamic tuberoinfundibular dopaminergic (TIDA) neurones secrete dopamine, which inhibits prolactin secretion (Khodr et al, 2009). Kisspeptin was found to reduce c-Fos expression in TIDA neurons leading to the suppression of TIDA activity and consequently decreases prolactin release thereby regulating its release. 


\section{Hot Flushes in Post-Menopausal Women}

A hot flush is characterized by episodic activation of heat dissipation effectors, including cutaneous vasodilatation, sweating, and behavioral thermoregulation (Freedman, 2012).

Hot flushes are closely timed with luteinizing hormone (LH) pulses, thereby linking it to the hypothalamic neural circuitry controlling pulsatile gonadotropin- releasing hormone $(\mathrm{GnRH})$ secretion (Casper et al, 1979). Current evidence suggests that pulsatile GnRH secretion is modulated by a subpopulation of neurons in the arcuate (infundibular) nucleus that express estrogen receptor $\alpha(E R \alpha)$, neurokinin 3 receptor (NK3R), kisspeptin, neurokinin B (NKB), and dynorphin (Rance et al, 2010). In the hypothalamus of postmenopausal women, these kisspeptin/NKB/ dynorphin (KNDy) neurons undergo an unusual somatic hypertrophy and express increased kisspeptin and NKB gene transcripts (Rance and Young, 1991). Studies of cynomolgus monkeys indicate that the changes in KNDy neurons in postmenopausal women are secondary to withdrawal of ovarian estrogens and not due to aging per se (Rometo et al, 2007). Consistent with this hypothesis, tract-tracing studies in the rodent showed that KNDy neurons project to structures critical for the regulation of body temperature (Krajewski et al, 2010) including the median preoptic nucleus (MnPO), an important component of a thermosensory heat-defense pathway (Nakamura et al, 2010).

\section{CLINICAL IMPLICATIONS}

A homozygous substitution of leucine to serine at nucleotide 148 (L148S) or heterozygous mutations at nucleotides 331 (R331X) and 399 (X399R) (Seminara et al, 2003), molecular analysis has shown the L148S mutation to inhibit the catalytic activation of $\mathrm{Gq}(\mathrm{G}-$ protein).

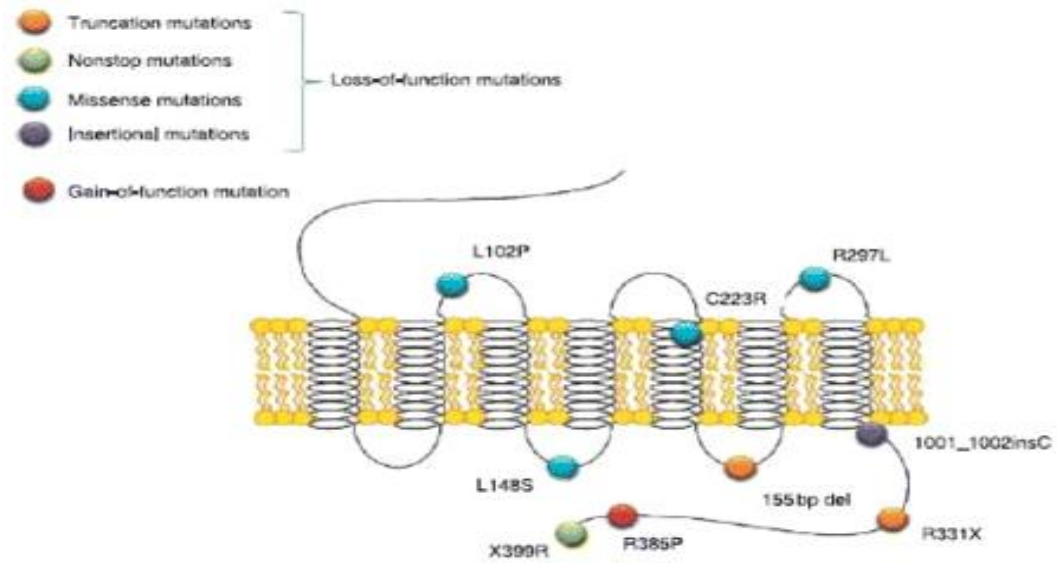

Fig. 6 shows the identified mutations in the human KISS1R gene which form the bases for pubertal and fertility disturbances (Seminara et al, 2003).

\section{Central Precocious Puberty}

Precocious puberty is characterized by the development of secondary sexual characteristics before the age of eight years in girls and nine years in boys. The premature activation of GnRH secretion leading to central precocious puberty has remarkable female gender predominance. The relevance of the kisspeptin system in human puberty onset was highlighted by the identification of activating mutations of the KISSIR and KISSI genes in children with central precocious puberty (Teles et al, 2008). A unique, heterozygous, non-constitutively activating mutation of the KISSIR gene was associated with a central precocious puberty phenotype. In vitro studies demonstrated that this mutation leads to sustained activation of intracellular signaling pathways in response to kisspeptin. A gain-of-function mutation (R386P) was reported in a girl with central precocious puberty (Teles et al, 2008).

\section{Delayed Puberty}

Kisspeptin as understood to be co-expressed with neurokinin $\mathrm{B}(\mathrm{NKB})$ and dynorphin, giving rise to the term KNDy neurons (Kisspeptin-Neurokinin B-Dynorphin). NKB is a member of the substance P-related tachykinin family and its receptor is expressed both on KNDy and GnRH neurons. Dynorphin is an opioid that participates in progesterone mediated negative feedback control of GnRH release. Loss-of-function mutations in the genes encoding neurokinin $\mathrm{B}(T A C 3)$ and its receptor (TAC3R) result in hypogonadotrophic hypogonadism and pubertal failure (Topaloglu et al, 2009). Moreover, in sexually mature fish, kisspeptin treatment led to 
increased gonad weight, gonadosomatic index, and spermatocrit in some white and striped bass. Additionally, mature white bass treated with kisspeptins showed advancement in oocyte development as determined by histological examination. These gonadal changes occurred in the absence of any photothermal manipulation or hormone injections.

\section{Gestational Trophoblastic Neoplasia (GTN)}

Gestational trophoblastic neoplasia (GTN) is a disease occurring mainly in pregnant women. GTN comprises a number of disorders characterized by an abnormal proliferation of placental tissue (Palmieri et al, 2005), but as has earlier been said of kisspeptin which increases during pregnancy, reduces trophoblast invasion therefore; a study was designed to determine whether plasma kisspeptin levels are altered in patients with malignant GTN. Blood samples were taken from patients with malignant GTN, it was found that kisspeptin IR was elevated in patients with malignant GTN; which was positively correlated with plasma hCG levels (Janneau et al, 2002), therefore GTN is presently diagnosed by measuring hCG. Chemotherapy treatment reduced kisspeptin IR and hCG levels in each patient (Palmieri et al, 2005).

\section{FUTURE CHALLENGES}

Despite the well characterized anatomic architecture of the Kisspeptin system in the CNS, there are several open questions regarding the actual roles of Kisspeptin in central and peripheral functions, viz: Have all kisspeptin receptors been identified?

Are there pre-synaptic inhibitory kisspeptin receptors in the brain?

One of the most intriguing questions concerns what roles does kisspeptins play in the periphery?

Do they act as hormones/paracrine mediators?

The presence of kisspeptins and their receptors in many peripheral organs such as small intestine, pancreas, liver, kidney, testes and placenta suggests that this may be the case. Cell lines and primary cultures from the CNS and peripheral tissues should provide a lot of missing information in this context.

\section{Summary and Conclusion}

In the course of this review, KISSPEPTIN a novel peptide has been given a special focus; the role of kisspeptins in the body cannot be over emphasized. Kisspeptin, a neuropeptide formerly known as metastin is a protein that is encoded by the KISS1 gene. It is found mainly in the Anteroventral periventricular nucleus (AVPV) and Arcuate nucleus (ARC) nuclei of the hypothalamus. Kisspeptin and its receptor, G-protein receptor 54 form a complex which mediates the onset of puberty and the maintenance of reproductive function throughout life. It carries out this function mainly by triggering the release of GnRH from the hypothalamus which leads to the release of gonadotrophins (FSH and LH) which are the main mediators of physiological and anatomical changes indicating the onset of puberty. KISS1 gene originally was identified as a human metastasis suppressor gene because of its ability to suppress melanoma, therefore it has also been found to suppress cancer cell invasion and migrations especially in breast and prostate cancers. Kisspeptin has also been found to have functions in other organs of the body, stimulating insulin secretion in the pancreas, acting as anti-oxidant especially in the liver, regulation of prolactin, aiding placentation and implantation in pregnancy, and increasing sensitivity of chemoreceptors in the type-1cells of the carotid bodies. The research on kisspeptin is still in an early phase, and scientists believe that cell line and primary cultures from both central and peripheral tissues should provide a lot of missing information encountered in the course of reviewing this important peptide.

\section{References}

[1] Aydin M, Oktar S, Yonden Z, Ozturk O H, Yilmaz B (2010). Direct and indirect effects of kisspeptin on liver oxidant and antioxidant systems in young male rats. Cell biochemistry and function. 28 (4): 293-9.

[2] Becker JA, Mirjolet JF, Bernard J (2005). "Activation of GPR54 promotes cell cycle arrest and apoptosis of human tumor cells through a specific transcriptional program not shared with other Gq-coupled receptors". Biochemistry Response Communication; 326:677-686.

[3] Bilban M, Ghaffari-Tabrizi N, Hintermann E, Bauer S, Molzer S, Zoratti C, Malli R, Sharabi AHiden U, Graier W (2004). "Kisspeptin-10, a KiSS-1/metastin-derived decapeptide, is a physiological invasion inhibitor of primary human trophoblasts". Journal of Cell Science; 117:1319-1328.

[4] Casper RF, Yen SSC, Wilkes MM (1979). "Menopausal flushes: A neuroendocrine linkwith pulsatile luteninizing hormone secreation”. Science; 205(4408):823-825.

[5] Castellano JM, Navarro VM, Fernandez-Fernandez R, Nogueiras R, Tovar S, Roa J, Vazquez MJ, Vigo E, Casanueva FF, Aguilar E (2005). "Changes in hypothalamic KiSS- 1 system and restoration of pubertal activation of the reproductive axis by kisspeptin in undernutrition". Endocrinology; 146: 3917-3925.

[6] Charlton H (2008). "Hypothalamic control of anterior pituitary function: a history". Jorunal Neuroendocrinology; 20 (6): 641-646. 
[7] Chehab FF, Lim ME \& Lu R (1996). "Correction of the sterility defect in homozygous obese female mice by treatment with the human recombinant leptin”. Nature Genetics; 12: $\quad 318-\quad 320$.

[8] Clements MK, McDonald TP, Wang R, Xie G, O'Dowd BF, George SR, Austin CP \& Liu Q (2001). "FMRFamide-related neuropeptides are agonists of the orphan G-protein-coupled receptor GPR54". Biochemical and Biophysical Research Communications; 284: 1189-1193.

[9] de la Iglesia HO, Schwartz W (2006). "Timely ovulation: circadian regulation of the female hypothalamo-pituitary-gonadal axis". Endocrinology; 147:1148-1153.

[10] de Roux N, Genin E, Carel JC, Matsuda F, Chaussain JL, Milgrom E (2003). "Hypogonadotropic hypogonadism due to loss of function of the KiSS1-derivedpeptide receptor GPR54". National Academic Science; 100:10972-10976.

[11] Dhillo, Waljit S.; Chaudhri, Owais B.; Patterson, Michael; Thompson, Emily L.; Murphy, Kevin G.; Badman, Michael K.; McGowan, Barbara M.; Amber, Vian; Patel, Sejal; Ghatei, Mohammad A.; Bloom, Stephen R. (2005). "Kisspeptin-54 stimulates the hypothalamic- pituitary gonadal axis in human males". Journal of Clinical Endocrinology and Metabolism; 90: 6609-6615.

[12] Dhillo, Waljit S.; Chaudhri, Owais B.; Patterson, Michael; Thompson, Emily L.; Murphy, Kevin G.; Badman, Michael K.; McGowan, Barbara M.; Amber, Vian; Patel, Sejal; Ghatei, Mohammad A.; Bloom, Stephen R. (2007). "Kisspeptin-54 stimulates the hypothalamic- pituitary gonadal axis in human males". Journal of Clinical Endocrinology and Metabolism; 92: 3958-3966.

[13] Downs JL, Wise PM (2009). "The role of the brain in female reproductive aging". Molecular Cellular Endocrinology; 299 (1): $32-$ 38.

[14] Funes S, Hedrick JA, Vassileva G, Markowitz L, Abbondanzo S, Golovko A, Yang S, Monsma FJ, Gustafson EL. (2003). "The KiSS-1 receptor GPR54 is essential for the developmentof the murine reproductive system". Biochemical and Biophysical Response Communication;312:1357-1363.

[15] Freedman RR (2001). "Physiology of hot flashes". Am J Hum Biology; 13(4):453-464.

[16] Gottsch ML, Cunningham MJ, Smith JT, Popa SM, Acohido BV, Crowley WF, Seminara S, Clifton DK \& Steiner RA (2004). “A role for kisspeptins in the regulation of gonadotropin secretion in the mouse". Endocrinology; 145: 4073-4077.

[17] Guyton AC and Hall JE. Textbook of Medical Physiology $12^{\text {th }}$ edition.

[18] Harms JF, Welch DR, Miele ME. (2003). "KISS1 metastasis suppression and emergent pathways". Clinical Exp Metastasis; 20:1118.

[19] Hines M (1982). "Prenatal gonadal hormones and sex differences in human behavior". Psychology Bull; 92 (1): 56-80.

[20] Hauge-Evans A. C., Richardson C. C., Milne H. M., Christie M. R., Persaud S. J., Jones P. M. (2006). “A role for kisspeptin in islet function". Diabetologia; 49 (9): 2131-2135.

[21] Iturriaga R, Alcayaga J (2004). "Neurotransmission in the carotid body: transmitters and modulators between glomus cells and petrosal ganglion nerve terminals". Brain Response Revised; 47:46-53.

[22] Janneau JL, Maldonado-Estrada J, Tachdjian G, Miran I, Motte N, Saulnier P, Sabourin JC, Cote JF, Simon B, Frydman R, Chaouat G, and Bellet D (2002). "Transcriptional expression of genes involved in cell invasion and migration by normal and tumoral trophoblast cells". Journal of Clinical Endocrinology and Metabolism; 87: 5336- 5339.

[23] Jeremy T Smith, Donald K Clifton and Robert A Steiner (2006). "Regulation of the neuroendocrine reproductive axis by kisspeptinGPR54 signaling”.Reproduction; 131: 623-630.

[24] Junko Tomikawa, Yoshihisa Uenoyama, Makiko Ozawa, Tatsuya Fukanuma, Kenji Takase, Teppei Goto, Hitomi Abe, Nahoko Ieda, Shiori Minabe, Chikaya Deura, Naoko Inoue, Makoto Sanbo, Koichi Tomita, Masumi Hirabayashi, Satoshi Tanaka, Takuya Imamura, Hiroaki Okamura, Kei-ichiro Maeda, and Hiroko Tsukamura (2012). "Epigenetic regulation of Kiss1 gene expression mediating estrogen-positive feedback action in the mouse brain". Proceedings of the national acdemy of sciences of the united states of America; 109(20): 7609-7610.

[25] Khodr CE, Hurley DL, Phelps CJ (2009). "Prolactin induces tuberoinfundibular dopaminergicneurone differentiation in Snell dwarf mice if administered beginning at 3 days of age". Journal Neuroendocrinology; 21(6):558-567.

[26] Kotani M, Detheux M, Vandenbogaerde A, Communi D, Vanderwinden JM, Le Poul E,Brézillon S, Tyldesley R, Suarez-Huerta N, Vandeput F, Blanpain C, Schiffmann SN, Vassart Parmentier M. (2001). "The metastasis suppressor gene KiSS-1 encodes kisspeptins, the natural ligands of the orphan G protein-coupled receptor GPR54”. Journal Biology and Chemistry; 276 (37): 34631 34636.Krajewski SJ, Burke MC, Anderson MJ, McMullen NT, Rance NE (2010). "Forebrain projections of arcuate neurokinin B neurons demonstrated by anterograde tracttracingand monosodium glutamate lesions in the rat". Neuroscience; 166(2):680-697.

[27] Lee DK, Nguyen T, O'Neill GP, Cheng R, Liu Y, Howard AD, Coulombe N, Tan CP, Tang- Nguyen AT, George SR (1999). "Discovery of a receptor related to the galanin receptors". FEBS Letters; 446: 103-107.

[28] Lee JH, Miele ME, Hicks DJ, Phillips KK, Trent JM, Weissman BE, Welch DR (1996). "KiSS-1, a novel human malignant melanoma metastasi ssuppressor gene". Journal National Cancer Institute; 88: 1731-1737.

[29] Meethal SV, Liu T, Chan HW, Ginsburg E, Wilson AC, Gray DN, Bowen RL, Vonderhaar BK, Atwood CS (2009). "Identification of a regulatory loop for the synthesis of neurosteroids: a steroidogenic acute regulatory protein-dependent mechanism involving hypothalamic-pituitary-gonadal axis receptors". Journal Neurochemistry; 110 (3): 1014-1027.

[30] Messager S (2005). "Kisspeptin and its receptor: new gatekeepers of puberty". Journal Neuroendocrinology; 17(10):687-688.

[31] Messager S, Chatzidaki EE, Ma D, Hendrick AG, Zahn D, Dixon J, Thresher RR, Malinge I, Lomet D, Carlton MB, Colledge WH, Caraty A, Aparicio SA (2005). "Kisspeptin directly stimulates gonadotropin-releasing hormone release via G protein-coupled receptor54". Proc National Academic Science USA; 102(5):1761-1766.

[32] Mitchell DC, Abdelrahim M, Weng J, Stafford LJ, Safe S, Bar-Eli M, Liu M (2006). "Regulation of KiSS-1 metastasis suppressor gene expression in breast cancer cells by direct interaction of transcription factors activator protein-2alpha and specificity protein-1". Journal Biology Chemistry; 281: 51-58.

[33] Moenter SM, Brand RC, Karsch FJ (1992). "Dynamics of gonadotropin-releasing hormone (GnRH) secretion during the GnRH surge: insights into the mechanism of GnRH surge induction". Endocrinology; 130:2978-2984.

[34] Moore RY, Eichler VB (1987). Loss of a circadian adrenal corticosterone rhythm following suprachiasmatic lesions in the rat. Brain Response; 42:201-206.

[35] Muir AI, Chamberlain L, Elshourbagy NA, Michalovich D, Moore DJ, Calamari A, SzekesPG, Sarau Chambers JK, Murdock P, Steplewski K, Shabon U, Miller JE, Middleton SE, Darker JG, Larminie CG, Wilson S, Bergsma DJ, Emson P, Faull R, Philpott KL, Harrison DC (2001). "AXOR12, a novel human G protein-coupled receptor, activated by the peptide KiSS-1". Journal Biology Chemistry; 276 (31):28969-28975.

[36] Nakamura K, Morrison SF (2010). "A thermosensory pathway mediating heat-defense responses". Proc National Academic Science USA; 107(19):8848-8853. 
[37] Navenot JM, Wang Z, Chopin M, Fujii N, Peiper SC (2005). "Kisspeptin-10-induced nefignaling of GPR54 negatively regulates chemotactic responses mediated by CXCR4: a potential mechanism for the metastasis suppressor activity of kisspeptins". Cancer Research; 65:10450-10456.

[38] Ohtaki T, Shintani Y, Honda S, Matsumoto H, Hori A, Kanehashi K, Terao Y, Kumano S,Takatsu Y, Masuda Y, Ishibashi Y, Watanabe T, Asada M, Yamada T, Suenaga M, Kitada C, Usuki S, Kurokawa T, Onda H, Nishimura O, Fujino M (2001). "Metastasis suppressor gene KiSS-1 encodes peptide ligand of a G-protein-coupled receptor". $\quad$ Nature; 411 (6837): 613617.

[39] Palm IF, Van Der Beek EM, Wiegant VM, Buijs RM, Kalsbeek A (1999). "Vasopressin induces a luteinizing hormone surge in ovariectomized, estradiol-treated rats with lesions of the suprachiasmatic nucleus". Neuroscience; 93:659-666.

[40] Palmieri C, Fisher RA, Sebire NJ, Lindsay I, Smith JR, McCluggage WG, Savage P, and Seckl MJ (2005). "Placental site trophoblastic tumour arising from a partial hydatidiform mole". Lancet; 366: 688.

[41] Park, So-Youn; Shin Hyun-Mu, Han Tae-Hee (2002). "Synergistic interaction of MEF2D and Sp1 in activation of the CD14 promoter". Molecular Immunology; 39 (1-2): 25-30.

[42] Pfaff DW, Vasudevan N, Kia HK, Zhu YS, Chan J, Garey J, Morgan M, Ogawa S (2000). "Estrogens, brain and behavior: studies in fundamental neurobiology and observations related to women's health". Journal Steroid Biochemistry and Molecular Biology; $30 ; 74(5): 365-373$.

[43] Pierotti, A. R. and A. J. Harmar. (1985). Multiple forms of somatostatin-like immunoreactivity in the hypothalamus and amygdala of the rat: selective localization of somatostatin-28 in the median eminence. J Endocrinol 105(3):383-389.

[44] Porzionato A, Macchi V, Parenti A, De Caro R (2008). "Trophic factors in the carotid body". InternationalRevisedCellular Molecular Biology; 269:1-58

[45] Rance NE, Young WS (1991). "Hypertrophy and increased gene expression of neurons containing neurokinin-B and substance-P messenger ribonucleic acids in the hypothalami of postmenopausal women". Endocrinology; 128(5):2239-2247.

[46] Rance NE, Krajewski SJ, Smith MA, Cholanian M, Dacks PA (2010). "Neurokinin B and the hypothalamicregulationof reproduction". Brain Response; 1364:116-128.

[47] Rometo AM, Krajewski SJ, Voytko ML, Rance NE (2007). "Hypertrophy and increased kisspeptin gene expression in the hypothalamic infundibular nucleus of postmenopausal women and ovariectomized monkeys". Journal of Clinical Endocrinology and Metabolism; 92(7):2744-2750.

[48] Seminara SB, Messager S, Chatzidaki EE, Thresher RR, Acierno JS, Jr, Shagoury JK, Bo- Abbas Y, Kuohung W, (2003). "The GPR54 gene as a regulator of puberty". New England Journal of Medicine; 349: 1614-1627.

[49] Sheehan HL, Kovács K (1966). "The subventricular nucleus of the human hypothalamus”.Brain; 89:589-614.

[50] Shepard KN, Michopoulos V, Toufexis DJ, Wilson ME (2009). "Genetic, epigeneticand environmental impact on sex differences in social behaviour". Physiology Behaviour; 97 (2): 157- 70.

[51] Szawka RE, Ribeiro AB, Leite CM, Helena CV, Franci CR, Anderson GM, Hoffman GE, Anselmo-Franci JA (2010). "Kisspeptin regulates prolactin release through hypothalamic dopaminergic neurons". Endocrinology; 151(7):3247-3257.

[52] Takino T, Koshikawa N, Miyamori H, Tanaka M, Sasaki T, Okada Y, Seiki M, Sato H(2003). "Cleavage of metastasis suppressor gene product KiSS-1 protein/metastin by matrix metalloproteinases”. Oncogenetics; 22:4617-4626.

[53] Teles MG, Bianco SDC, Brito VN, et al (2008). "A GPR54-activating mutation in a patient with central precocious puberty". Journal Medicine; 358:709-715

[54] Tena-Sempere M (2006). "GPR54 and kisspeptin in reproduction”. Human Reproduction Update; 12: 631-639.

[55] Thompson EL, Murphy KG, Patterson M, Bewick GA, Stamp GW, Curtis AE, Cooke JH, Jethwa PH, Todd JF, Ghatei MA (2006). "Chronic subcutaneous administration of kisspeptin-54 causes testicular degeneration in adult male rats". Journal of Physiology and Endocrinology and Metabolism; 291:E1074-E1082.

[56] Topaloglu A.K, Reimann F, Guclu M, Yalin AS, Kotan LD, Porter KM, Serin A, Mungan NO, Cook JR, Ozbek MN, Imamoglu S, Akalin NS, Yuksel B, O'Rahilly S, Semple RK (2009). "TAC3 and TACR3 mutations in familial hypogonadotropic hypogonadism reveal a key role for Neurokinin B in the central control of reproduction". Nat Genetics; 41:354-358.

[57] Topaloglu AK, Tello JA, Kotan LD (2012). "Inactivating KISS1 mutation andhypogonadotropic hypogonadism". New England Journal of Medicine;366:629-635.

[58] Vadakkadath Meethal S, Atwood CS (2005). "The role of hypothalamic-pituitary- gonadal hormones in the normal structure and functioning of the brain". Cellular Molecular Life Science; 62 (3): 257-270.

[59] Wilbur P. Williams, Stephan G. Jarjisian, Jens D. Mikkelsen, and Lance J. Kriegsfeld (2011) "Circadian Control of Kisspeptin and a Gated GnRH Response Mediate the Preovulatory Luteinizing Hormone Surge”. Endocrinology; 152(2): 595-606.

[60] Xavier d'Anglemont de Tassigny and William Henry Colledge (2010). "The Role of Kisspeptin Signaling in Reproduction". PHYSIOLOGY; 25: 207-217.

[61] Yamada, S., Y. Uenoyama, M. Kinoshita, K. Iwata, K. Takase, H. Matsui, S. Adachi, K. Inoue, K. I. Maeda, and H. Tsukamura. (2007). Inhibition of metastin (kisspeptin-54)- GPR54 signaling in the arcuate nucleus-median eminence region during lactation in rats. Endocrinology 148(5):2226-2232.

[62] Zhang Y, Proenca R, Maffei M, Barone M, Leopold L \& Friedman JM (1994). "Positional cloning of the mouse obese gene and its human homologue". Nature; 372: 425-432. 